\title{
Transposição dentária maxilar bilateral: relato de um caso
}

\author{
Bilateral maxilar dental transposition: case report
}

Evelyn Gomberg ${ }^{1}$, José Roberto de Menezes Pontes ${ }^{2}$, Mônica Israel ${ }^{3}$, Maria Eliza Ramos ${ }^{4}$

\begin{abstract}
${ }^{1}$ Acadêmica do oitavo período de Odontologia - Universidade do Estado do Rio de Janeiro. ${ }^{2}$ Tecnologista do Instituto Nacional de Câncer, cedido à disciplina de Estomatologia da Faculdade de Odontologia da UERJ. ${ }^{3}$ Professora Substituta da disciplina Estomatologia - Faculdade de Odontologia - UERJ. ${ }^{4}$ Professora Adjunta da disciplina Estomatologia Faculdade de Odontologia - UERJ.
\end{abstract}

\begin{abstract}
Resumo
A transposição dentária é uma anomalia rara, que consiste na troca de posição entre dois dentes permanentes em um mesmo quadrante do arco dental. Sua etiologia ainda não é clara, mas há algumas teorias para explicá-la. O diagnóstico se dá pelo exame clínico. Radiograficamente, pode-se determinar se a transposição é completa ou incompleta. 0 tratamento pode ser protético, restaurador ou ortodôntico. 0 objetivo deste trabalho é relatar um caso de transposição bilateral na maxila, que acometeu os caninos e primeiros pré-molares superiores nos dois lados. Nesse caso, a transposição foi diagnosticada em consulta odontológica com objetivo de tratar doença periodontal. Foi realizado exame clínico e radiográfico, assim como tratamento periodontal e restaurador. Em relação à transposição dentária, o paciente relatou não se incomodar com a situação e optou por não intervir. Após a discussão de alguns fatores relacionados à condição, concluiu-se que a transposição tem difícil tratamento, já que a correção ortodôntica e a modificação da anatomia dental são procedimentos complexos. Os riscos do tratamento devem ser avaliados e, caso não incomode o paciente e não gere distúrbios funcionais, não há necessidade de intervir.

Palavras- chave: Transposição dentária.
\end{abstract}

\section{Abstract}

The dental transposition is a rare anomaly, which is the exchange of position between two permanent teeth in one quadrant of the dental arch. Its etiology is unclear, but there are some theories to explain it. The diagnosis is through clinical examination. Radiographically, one can determine whether the transfer is complete or incomplete. The treatment can be prosthetic, restorative or orthodontic. This study reports a case of bilateral transposition in the jaw, which affected the canines and first premolars on both sides. In this case, the transposition was diagnosed with dental visit in order to treat periodontal disease. Was carried out clinical and radiographic examination, as well as periodontal and restorative treatment. Regarding dental transposition, the patient reported no discomfort with the situation and chose not to intervene. After discussion of some factors related to the condition it was concluded that incorporation is difficult to treat because the orthodontic correction and modification of dental anatomy are complex procedures. The risks of treatment should be assessed and, if they bother the patient and do not cause functional disorders, there is no need to intervene.

Keywords: Dental transposition.

\section{INTRODUÇÃO}

A transposição dentária pode ser definida como a troca de posição entre dois dentes permanentes em um mesmo quadrante do arco dental ${ }^{1,2}$. Consiste em uma anomalia rara, que acomete 0,3 a 0,4\% dos indivíduos ${ }^{3,}$ ${ }^{4}$. A maxila é mais afetada que a mandíbula ${ }^{2,3,5}$, sendo o canino superior o dente mais comumente envolvido ${ }^{2}$. Na maxila, a transposição é mais frequente entre o canino e o primeiro pré-molar ${ }^{2,3,4,6}$, seguida pela transposição entre o canino e o incisivo lateral ${ }^{1,2,3}$. Na mandíbula, é mais comum a troca de posição do canino com o incisivo lateral ${ }^{3}$. O acometimento unilateral é mais comum que o bilateral ${ }^{2}$, e o lado esquerdo é o Recebido em 10 de maio de 2009; revisado em 30 de novembro de 2010. Correspondência / Correspondence: Mônica S. Israel. Rua Crundiúba, 555/301 - Jardim Carioca - Ilha do Governador. 21931-500 Rio de Janeiro - RJ - Brasil. E-mail: monicasisrael@yahoo.com.br mais frequentemente envolvido 2, 3, 4 . Essa condição ocorre em ambos os sexos, com preferência pelo sexo feminino. ${ }^{2,3}$

A transposição dentária pode ocorrer em associação com outras anomalias congênitas como a hipodontia, incisivos laterais conoides, giroversão, retenção de dentes decíduos, dilaceração e má formação de dentes adjacentes ${ }^{1,4,6}$. A sua etiologia ainda não está clara, mas há algumas teorias que tentam explicar esse processo. São elas: transposição da lâmina dentária durante a odontogênese, migração intraóssea do germe dentário, consequência da retenção ou perda precoce do dente decíduo, em decorrência de um trauma, ou predisposição genética. ${ }^{1,2,3,4,6}$

O diagnóstico baseia-se no exame clínico. Radiograficamente, pode-se determinar se a transposição é completa ou incompleta. Na transposição 
completa, tanto as coroas quanto as raízes dos dentes envolvidos estão em posições trocadas. $\mathrm{Na}$ incompleta, apenas as coroas estão em posição trocada; o ápice radicular dos dois elementos encontra-se na posição correta 2, 3, . O exame radiográfico é também um auxiliar no planejamento do tratamento ortodôntico.

A opção pelo tratamento ou não vai depender do interesse do paciente em modificar sua condição, e da possibilidade de um tratamento bem sucedido. As opções de tratamento são a modificação da anatomia dentária, o tratamento ortodôntico ${ }^{3,5}$ ou tratamento protético. O primeiro consiste em desgastes e reconstrução da anatomia em resina para que os dentes em posição trocada fiquem parecidos com o dente que normalmente ocupa aquela posição. Para que a modificação anatômica tenha sucesso, os dentes transpostos não podem ter anatomias muito diferentes entre si. O tratamento ortodôntico consiste na movimentação dentária visando a modificar a posição dos elementos que sofreram transposição. A intervenção ortodôntica precoce é o tratamento de escolha para essa condição, mas se os dentes permanentes já tiverem irrompido, o tempo de tratamento se torna muito longo ${ }^{3}$. Além disso, essa movimentação nem sempre é possível, porque exige que a tábua óssea tenha espessura suficiente para abrigar as raízes dos dois elementos superpostas, sem que ocorra deiscência ou fenestração 3,4 . E como o canino costuma ter uma raiz bem calibrosa, isso muitas vezes acaba ocorrendo.A terceira opção de tratamento seria o tratamento protético. Pode ser feito preparo para coroa total, o que, muitas vezes, pode resultar em necessidade de tratamento endodôntico e posterior confecção de uma coroa no formato do dente correto. Ou então, o dente trocado pode ser extraído ${ }^{5} \mathrm{e}$ substituído por um implante ou um pôntico, sendo essa a última opção, indicada apenas em casos em que todas as outras formas de tratamento são inviáveis e que o paciente se incomode muito com sua condição.

O objetivo deste estudo é acrescentar à literatura um caso de transposição bilateral na maxila entre canino e primeiro pré-molar.

\section{RELATO DE CASO}

Paciente do sexo masculino, melanoderma, 37 anos, apresentou-se para consulta odontológica com queixa principal de "dentes moles". Ao exame clínico, notou-se a presença de doença periodontal, cáries, fratura coronária do dente 23 e transposição dentária entre o 13 e o 14, estando esse último girovertido. Através do exame periapical completo, a transposição dentária foi classificada como completa e observou-se dilaceração radicular do elemento 13 . Os dentes 23 e 24 também se apresentavam com transposição. Foram realizados o tratamento periodontal e as restaurações necessárias. Em relação à transposição dentária ,o paciente relatou não se incomodar com a situação e optou pela nãointervenção terapêutica.

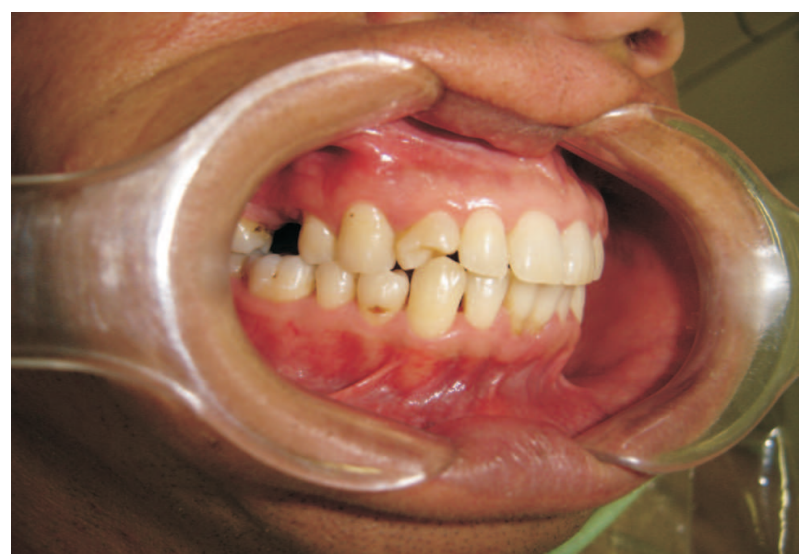

Figura 1 - Transposição entre os elementos 13 e 14, estando esse último girovertido.

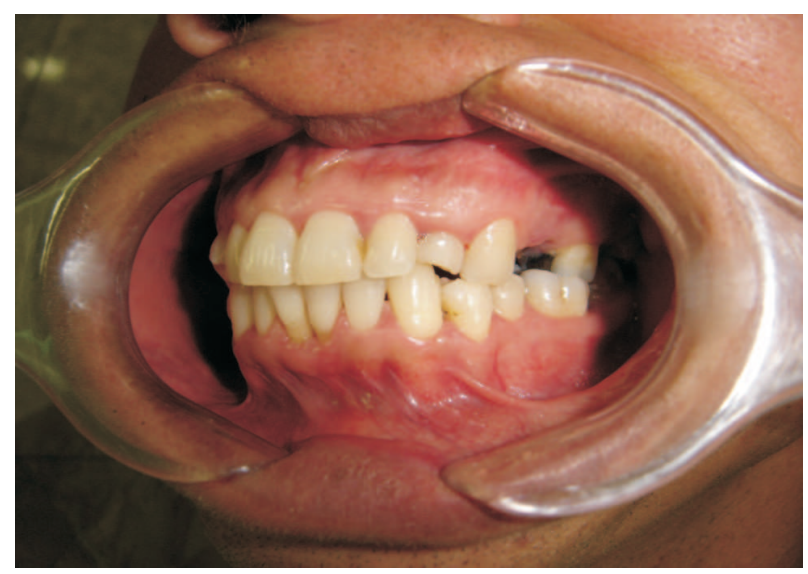

Figura 3 - Radiografia que mostra a transposição completa entre os elementos 13 e 14

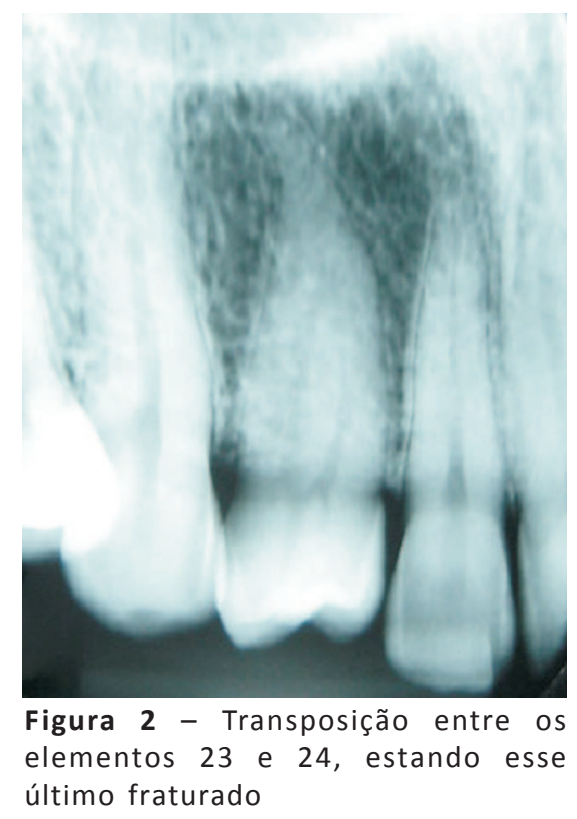

\section{DISCUSSÃO}

A transposição dentária é, por si só, uma condição rara, acometendo 0,3 a $0,4 \%$ dos indivíduos ${ }^{3,4}$. 
Geralmente é unilateral ${ }^{2}$ e mais comum na maxila ${ }^{2,3,7}$. No nosso caso, a transposição ocorreu na maxila; entretanto, foi bilateral, o que torna o achado ainda mais incomum. Nosso paciente apresentava transposição entre os caninos e os primeiros prémolares superiores, ratificando os relatos da literatura que apontam esses dentes como os mais envolvidos ${ }^{2,3,}$ 4, 6 . Embora o sexo feminino seja mais acometido ${ }^{2,3}$, estamos relatando uma ocorrência no sexo masculino.

É comum a associação da transposição com outras anomalias dentárias, tais como: hipodontia, incisivos laterais conoides, giroversão, retenção de dentes decíduos, dilaceração e má formação de dentes adjacentes $^{1,4,6}$. Nosso paciente apresentava giroversão do primeiro pré-molar superior direito transposto.

A transposição foi diagnosticada no exame clínico, e o exame radiográfico periapical permitiu classificar a transposição como completa, uma vez que tanto as coroas como as raízes dos elementos estavam em posições trocadas. ${ }^{2,3,4}$

O tratamento para nosso paciente seria um pouco mais difícil, em função de o dente transposto apresentarse girovertido. Isso dificultaria a modificação da anatomia e também a correção ortodôntica. Além disso, a correção ortodôntica estaria contraindicada, já que o paciente apresentava 37 anos, e a movimentação ortodôntica após a erupção completar-se torna-se muito demorada e complexa ${ }^{3}$ e só poderia ser iniciada após tratamento periodontal, uma vez que o paciente apresentava periodontite ${ }^{8}$. Além disso, o canino superior direito apresentava dilaceração radicular, o que dificultaria ainda mais o movimento ortodôntico. A estabilidade do caso seria pequena, devido ao problema periodontal do paciente e também pelo fato de um dos elementos envolvidos apresentar-se girovertido. A correção de um dente com giroversão necessita de um longo tempo de contenção para que o dente não volte à posição original, e ainda assim há recidiva na grande maioria dos casos ${ }^{8}$. Isso ocorre em função da resistência e elasticidade das fibras do ligamento periodontal, que têm memória elástica. As fibras gengivais permanecem estiradas com memória elástica por 232 dias $^{9}$. No caso do paciente em questão, a opção seria a confecção de coroa total. Provavelmente, haveria necessidade de tratamento endodôntico, uma vez que o dente apresentava giroversão.

O paciente, entretanto, optou por não se submeter ao tratamento. Afinal, ele tinha 37 anos de idade e nunca tinha reparado ser portador de transposição dentária; a condição só foi identificada em consulta odontológica. Para ele, aquilo não incomodava em nada, até porque sua situação dentária já se encontrava prejudicada, uma vez que possuía periodontite.

\section{REFERÊNCIAS}

1 GRANT, J.E.R.; MEZIER, N.A.; DIBIASE, A.T. Mandibular first and second molar tooth transposition: a case report. Int. J. Paediatr. Dent., Oxford, v.16, p.227-229, May 2006.
2 SHAPIRA, Y.; KUFTINEC, M.M. Maxillary tooth transpositions: chracteristic features and accompanying dental anomalies. Am.J. Orthod. Dentofac. Orthop., St. Louis, v.119, p.127-134, Mar. 2001.

3 MAIA, F.A.; MAIA, N.G. Transposição de canino com o incisivo lateral inferior: uma visão ortodôntica. R. Dent. Press Ortodon. Ortop. Facial, Maringá, v.5, n.6, p.79-88, nov./dez. 2000.

4 MAIA, F.A.; MAIA, N.G. Unusual orthodontic correction of bilateral maxillary canine-first premolar transposition. Angle Orthod., Appleton, v.75, n.2, p.266-276, Mar. 2005.

5 NEVILLE, B.W. et al. Patologia oral e maxilofacial. 2.ed. Rio de Janeiro: Guanabara Koogan, 2004.

6 CAMILLERI, S. Maxillary canine anomalies and tooth agenesis. Eur. J. Orthod., Oxford, v.27, p.450-456, Oct. 2005.

7 PECK, S.; PECK, L.; KATAJA, M. Mandibular lateral incisor-canine transposition, concomitant dental anomalies, and genetic control. Angle Orthod., Appleton, v.68, n.5, p.455-466, Oct. 1998.

8 MOYERS, R.E. Ortodontia. 4.ed. Rio de Janeiro: Guanabara Koogan, 1991.

9 BOISE, L.R. Fiberotomy and reproximation without lower retention, nine years in retrospect: part II. Angle Orthod., Appleton, v.50, n.3, p.169-178, July 1980 